\title{
ENSINO A DISTÂNCIA, DIFICULDADES PRESENCIAIS: PERSPECTIVAS EM TEMPOS DE COVID-19
}

\author{
ENSEÑANZA A DISTANCIA, DIFICULTADES PRESENCIALES: PERPECTIVAS EN \\ TIEMPOS DEL COVID - 19
}

\author{
DISTANCE LEARNING, FACE TO FACE DIFFICULTIES: PERSPECTIVES IN \\ TIMES OF COVID-19
}

Thaís Janaina WENCZENOVICZ ${ }^{1}$

\begin{abstract}
RESUMO: Por causa da pandemia, as escolas brasileiras suspenderam as aulas presenciais em meados de março de 2020 e passaram a buscar formas alternativas de manter o processo de ensino-aprendizagem durante a quarentena. Ou seja, as tecnologias - aplicativos e plataformas on-line - recepcionaram status de excelência nos espaços educacionais. O estudo analisa as dificuldades impostas à concretização do processo de ensino-aprendizagem em razão das imposições da pandemia incidindo sobre o Direito Humano à educação. Do ponto de vista metodológico, o recorte temporal escolhido para tratar do tema será de dezembro de 2019 até maio de 2020, contexto que receberá uma abordagem crítico-científica, desvelandose, assim, o Direito Humano à educação como discurso e não apenas como norma. Utiliza-se do procedimento metodológico bibliográfico-investigativo com acréscimo de banco de dados e estatísticas do INEP, acrescidos da fala de dez educadores (entrevistas on-line).
\end{abstract}

PALAVRAS-CHAVE: COVID-19. Direitos humanos. Ensino a distância.

RESUMEN: Debido a la pandemia del virus Covid 19 las escuelas brasileras suspendieron las clases presenciales a mediados de marzo del 2020 y comenzaron a buscar formas alternativas de mantener el proceso de enseñanza-aprendizaje durante la cuarentena. Las tecnologías TIC (tecnología de la información y comunicación) con sus aplicativos y plataforma en línea (conexión hombre maquina en internet) recibieron estado de excelencia en los espacios educacionales. El estudio analiza las dificultades impuestas a la concretización del proceso enseñanza-aprendizaje en razón de las imposiciones de la pandemia que afecta el derecho a la educación. Desde un punto metodológico y el tramo temporal escogido para tratar el tema será diciembre del 2019 hasta mayo del 2020, el contexto recibirá un abordaje critico-científico, enfatizando el Derecho Humano a la Educación como discurso y no solo como una norma. Se usa el procedimiento metodológico bibliográfico-investigativo y el uso de la base de datos y estadística del INEP, además de la opinión de diez educadores (entrevista en línea).

PALABRAS CLAVE: COVID-19. Derechos humanos. Enseñanza a distancia.

${ }^{1}$ Universidade Estadual do Rio Grande do Sul (UERGS), Erechim - RS - Brasil. Professora Titular no Programa de Pós-Graduação em Educação (UERGS) e no Programa de Pós-Graduação em Direito (UNOESC) e Professora Colaboradora no Programa de Pós-graduação em Educação (UNIOESTE). Pós-Doutorado (UNIOESTE). ORCID: http://orcid.org/0000-0001-9405-3995 E-mail: t.wencze@terra.com.br

RIAEE - Revista Ibero-Americana de Estudos em Educação, Araraquara, v. 15, n. 4, p. 1750-1768, out./dez. 2020. e-ISSN: $1982-5587$. 
ABSTRACT: Because of the pandemic, Brazilians' schools have suspended classroom lessons in mid-March 2020 and they have started to search for alternatives to keep the process of teaching and learning during the quarantine. In other words, the technologies, apps and on-line platforms have got excellence status in the educational spaces. The study analyzes the difficulties that are imposed to accomplish the process of teaching and learning, because of the pandemic focusing on the right to education. About the methodology, the part of the time that was chosen to study was December 2019 until March 2020. This contest will be approached by a crucial and scientific exam that will show the Humans Rights to education as a speech and not just a rule. The procedure that was used of bibliography and research methodology, and also the database and statistics from INEP and speeches of 10 educators (on-line interview).

KEYWORDS: COVID-19. Humans rights. Distance learning.

\section{Introdução}

A educação é um direito humano e aponta para um horizonte de conquistas. A educação como Direito Humano, ou direitos que valem para todos, surge para as sociedades entenderem a irracionalidade que é a banalização da vida, sendo que o êxito nos enfrentamentos dos problemas advém do pensar, do teorizar, de esclarecer os fatos e reconhecer as coletividades como portadores de direitos.

Ao postularem a educação como um direito, os autores da Declaração Universal dos Direitos Humanos basearam-se, axiomaticamente, na noção de que a educação não é neutra em relação a valores. Por isso, o Artigo 26, em sua seção mais controversa, determina que o direito à educação se vincula a três objetivos específicos: (1) pleno desenvolvimento da personalidade humana e fortalecimento do respeito aos direitos do ser humano e às liberdades fundamentais; (2) promoção da compreensão, da tolerância e da amizade entre todas as nações e a todos os grupos raciais e religiosos; e (3) incentivo às atividades da ONU para a manutenção da paz.

Nessa seara, o Artigo 26 estabelece uma série de metas educacionais, analisadas aqui juntamente com a discussão que focaliza a educação como um Direito Humano em tempos de pandemia. O estudo utiliza-se do procedimento metodológico bibliográfico-investigativo, acrescido de dados e bases estatísticas de organismos como o IBGE, INEP, UNICEF e o Sistema de Vigilância Alimentar e Nutricional do Ministério da Saúde/SISVAM.

A reflexão também se desenvolve fundamentada em estudos e escuta dos sujeitos relacionados à educação formal, para construir uma memória sobre a tomada de decisões iniciais, que aos poucos são sistematizadas, quanto aos modos de realização da prática pedagógica, as quais têm demonstrado fragilidades, uma vez que a substituição das aulas 
presenciais pelo 'ensino remoto' não é suficiente, tampouco se configura numa modalidade organizada em $\mathrm{EaD}$ (Educação a distância), no favorecimento e garantia da equidade e qualidade da educação. Os dados a seguir fazem parte de uma pesquisa, pontualmente situada e em andamento, sobre os entendimentos dos sujeitos da educação: professores. Nesse sentido, destaca-se ouvir e analisar os entre-lugares dos protagonistas da escola em tempos de pandemia. Foram entrevistados 10 educadores, sendo cinco atuantes em escola pública e cinco em escola privada.

\section{Colonialismo e Colonialidade: reflexões pontuais}

Pensar na composição social do Brasil leva a retomar o processo histórico de exclusões e apagamentos sociais empenhados no decorrer das últimas décadas. Fruto de um processo de ocupação e povoamento assentado no colonialismo, na colonialidade do poder, do saber e do ser, o Brasil ressignifica a cada ciclo sua negação de direitos para uma parte significativa da população nacional.

Cabe ressaltar que o termo "colonialismo" é conceituado por Quijano (2009, p. 73) como uma "estrutura de dominação/exploração onde o controle da autoridade política, dos recursos de produção e do trabalho de uma população determinada domina outra de diferente identidade e cujas sedes centrais estão, além disso, localizadas noutra jurisdição territorial”. Objetivando discutir o colonialismo e seus desdobramentos, especificamente na conjuntura da América Latina, foi formado no final da década de 90 o Grupo Modernidade/Colonialidade ${ }^{2}$.

De acordo com os pensadores afiliados no Grupo Pensadores do Sul, as relações de colonialidade nos âmbitos econômico e político não cessaram com o fím do colonialismo e suas administrações coloniais, permanecendo em contínua reprodução pelas culturas e estruturas capitalistas modernas/coloniais do sistema-mundo ${ }^{3}$, por meio do controle da economia, da autoridade, da natureza e dos recursos naturais, do gênero e da sexualidade, da

${ }^{2}$ Para aprofundamento sobre a gênese do grupo latino-americano Modernidade/Colonialidade e sua relação com os debates a respeito do colonialismo projetados de outros locais (como as teorias pós-coloniais de autores da África, Índia etc.), consultar Ballestrin (2013).

${ }^{3}$ O sociólogo estadunidense Immanuel Wallerstein publicou, em 1974, a obra "The modern world-system. Capitalist agriculture and the origins of the European world-economy in the 16th. century", na qual desenvolveu a teoria do sistema-mundo, defendendo, em síntese, que, no mundo moderno, os acontecimentos passaram a ocorrer em um palco mais amplo, o que chama de sistema-mundo moderno, que corresponde à economia mundial capitalista (sistema econômico que é interconectado em escala global), cujo início remonta a aproximadamente o século XVI, perdurando até a atualidade. O sistema-mundo moderno teria nascido com a constituição das Américas, territórios que não foram incorporados a uma já existente economia mundial capitalista, mas, sim, foram determinantes para a emersão de uma economia mundial capitalista, apontando-se três elementos fundamentais: a) a expansão geográfica do mundo; b) o desenvolvimento de diversos métodos de controle do trabalho para diferentes produtos e diferentes zonas da economia mundial (centro, periferia e semiperiferia); c) a criação de mecanismos burocráticos estatais (QUIJANO; WALLERSTEIN, 1992, p. 549). 
subjetividade e do conhecimento, em uma tripla dimensão, isto é, colonialidade do poder, do saber e do ser (BALLESTRIN, 2013).

Com efeito, a modernidade ocidental se sustentou em um "pensamento abissal", dividindo a realidade social em dois mundos: o "deste lado da linha", isto é, sociedades metropolitanas (colonizadoras), Direito (legal ou ilegal, consoante o arcabouço jurídico oficial do Estado ou internacional) e conhecimento científico; e o "do outro lado da linha", ou seja, territórios coloniais, "conhecimentos populares, leigos, plebeus, camponeses ou indígenas" (que são eliminados como "conhecimentos relevantes ou comensuráveis por se encontrarem para além do universo do verdadeiro e do falso", constituindo meras "crenças, opiniões, magia, idolatria, entendimentos intuitivos ou subjetivos") e "território sem lei, fora da lei, o território do a-legal, ou mesmo do legal e ilegal de acordo com direitos não reconhecidos oficialmente" (SANTOS, 2007, p. 72-73).

Conforme Boaventura de Sousa Santos:

Na sua constituição moderna, o colonial representa não o legal ou o ilegal, mas o sem lei. Uma máxima que então se populariza, "Não há pecados ao sul do Equador", ecoa na famosa passagem dos Pensamentos de Pascal, escritos em meados do século XVII: "Três graus de latitude subvertem toda a jurisprudência. Um meridiano determina a verdade [...]. Singular justiça que um rio delimita! Verdade aquém dos Pirineus, errado além". De meados do século XVI em diante, o debate jurídico e político entre os Estados europeus acerca do Novo Mundo concentra-se na linha global, isto é, na determinação do colonial, e não na ordenação interna do colonial. O colonial é o estado de natureza, onde as instituições da sociedade civil não têm lugar. [...] A zona colonial é por excelência o universo das crenças e dos comportamentos incompreensíveis, que de forma alguma podem ser considerados como conhecimento e por isso estão para além do verdadeiro e do falso. O outro lado da linha alberga apenas práticas mágicas ou idolátricas, cuja completa estranheza conduziu à própria negação da natureza humana de seus agentes (SANTOS, 2007, p. 73-75).

Foi no outro lado da linha abissal, na "face oculta e essencial" da Modernidade, que se desenvolveu "o mundo periférico colonial, o índio sacrificado, o negro escravizado, a mulher oprimida, a criança e a cultura popular alienadas", ou seja, "as vítimas da Modernidade", atingidas pelo "ato irracional (como contradição do ideal racional da própria Modernidade)" (DUSSEL, 2005, p. 29; BRAGATO, 2014).

Nas palavras de Castro-Gómez (2005, p. 80), a modernidade consiste em uma "máquina geradora de alteridades que, em nome da razão e do humanismo, exclui de seu imaginário a hibridez, a multiplicidade, a ambiguidade e a contingência das formas de vida concretas", suprimindo todas as diferenças. E, na conjuntura do "projeto moderno", as Ciências Sociais serviram como ferramentas para produzir alteridades, manejadas conforme 
as exigências da "acumulação de capital", para formação de "um perfil de sujeito" (de subjetividade) adaptado à produção, isto é, "branco, homem, casado, heterossexual, disciplinado, trabalhador, dono de si mesmo". Tal padrão de "homem racional" foi elaborado por meio da contraposição com o "outro da razão", ou seja, "o louco, o índio, o negro, o desadaptado, o preso, o homossexual, o indigente" (CASTRO-GÓMEZ, 2005, p. 80). Pelo colonialismo, então, o homem europeu e burguês tornou-se "um sujeito/agente, apto a decidir, para a vida pública e o governo, um ser de civilização, heterossexual, cristão, um ser de mente e razão", e, assim, passou a ser tomado como a "medida de todas as coisas" (LUGONES, 2014, p. 936-937).

Na década de 1970, formava-se no sul asiático o Grupo de Estudos Subalternos - com a liderança de Ranajit Guha, indiano que assentou seus estudos em uma crítica à historiografia eurocêntrica nacionalista indiana. Na década de 1980, os subaltern studies se tornaram conhecidos fora da Índia, especialmente através dos autores Partha Chatterjee, Dipesh Chakrabarty e Gayatri Chakrabarty Spivak. ${ }^{4}$

O termo "subalterno" começou a ser utilizada nos anos 1970, na Índia, como referência às pessoas colonizadas do subcontinente sul-asiático, e possibilitou um novo enfoque na história dos locais dominados, até então vistos apenas do ponto de vista dos colonizadores e seu poder hegemônico. Emergiria, assim, o nome "subalternidade" que, de nome abstrato, teria seu sentido deslocado para certa concretude e visibilidade (FIGUEIREDO, 2010, p. 2)

\section{Ensino a distância e Educação emergencial remota: questões pontuais em um país desigual}

A desigualdade marca a trajetória histórica do Brasil. A educação, tendo como função central o processo de escolarização, é um fator capaz de desenvolver nos indivíduos suas potencialidades ao permitir o "pleno desenvolvimento da pessoa, seu preparo para o exercício da cidadania e sua qualificação para o trabalho", como previsto na Constituição de 1988. Quando disseminada de forma universal pode ser um relevante mecanismo para a promoção

\footnotetext{
${ }^{4}$ Spivak apresentou o trabalho do grupo ao público estadunidense, sendo ela uma das mais importantes tradutoras de Jaques Derrida. Em 1985, Spivak publicou um artigo que tornou-se outro cânone do póscolonialismo: "Pode o subalterno falar?". Nesse artigo, a autora faz uma crítica aos intelectuais ocidentais Deleuze e Foucault em razão da filiação pós-estruturalista e desconstrucionista e uma autocrítica aos estudos subalternos, através da reflexão sobre a prática discursiva do intelectual pós-colonial. Para ela, o sujeito subalterno é aquele cuja voz não pode ser ouvida; sua crítica à intelectualidade que pretende falar em seu nome é ao fato de que "nenhum ato de resistência pode ocorrer em nome do subalterno sem que esse ato seja imbricado no discurso hegemônico" (ALMEIDA, 2010, p. 12).
} 
de oportunidades para a coletividade. E, em países que se destacam pela desigualdade, ganha maior relevo a responsabilidade do poder público.

De acordo com estudo da Fundação Getúlio Vargas (2019), a desigualdade cresceu no Brasil e registrou aumento persistente no segundo semestre de 2019, superando o pico histórico observado em 1989. Publicado pelo Centro de Políticas Sociais da Fundação, o estudo avaliou as mudanças nos índices de desigualdade nos últimos sete anos e suas relações com o crescimento, as consequências sobre o bem-estar social e a pobreza. Segundo o documento, enquanto a renda da metade mais pobre da população caiu cerca de $18 \%$, somente o $1 \%$ mais rico teve quase $10 \%$ de aumento no poder de compra. Ou seja, nem em 1989, ano considerado pico histórico de desigualdade brasileira, houve um movimento de concentração de renda por tantos períodos consecutivos.

Apenas em 2015, a pobreza subiu 19,3\% no Brasil, com 3,6 milhões de novos pobres. Desde o segundo trimestre do mesmo ano até 2017 , a população vivendo na pobreza no país aumentou $33 \%$, atingindo $11,2 \%$ dos brasileiros, contra os $8,4 \%$ antes registrados. O estudo baseia-se na Pesquisa Nacional por Amostra de Domicílio Contínua (PNADC), do IBGE, e no índice de Gini ${ }^{5}$, medidor global de desigualdade. Concomitante ao crescimento das desigualdades vem o aumento de demandas das populações empobrecidas para o Estado e, por consequência, o distanciamento de acesso aos direitos humanos fundamentais e, dentre eles, o direito à educação. Segundo dados do UNICEF (2018), 43,8\% das crianças e dos adolescentes de 5 a 14 anos vivem em domicílios com renda per capita de até 1/2 salário mínimo.

A negação do direito à educação surge praticamente com o processo de colonização. A exclusão de centenas de cidadãos de acesso à escola consolidou os processos de segregação e vulnerabilização de milhares de cidadãos no Brasil. Segundo José Ricardo Pires de Almeida (2000, p. 37), no Brasil Colônia "havia um grande número de negociantes ricos que não sabiam ler". Prova disso confirma-se pelo fato de que no Império admitia-se o voto do analfabeto desde que este possuísse bens e títulos. No mesmo trabalho, Almeida mostra que, em 1886, enquanto o porcentual da população escolarizada no Brasil era de apenas 1,8\%, na Argentina este índice era de 6\%.

${ }^{5} \mathrm{O}$ índice de Gini é a medida mais popular de desigualdade, variando entre 0 (perfeita igualdade) e 1 (perfeita iniquidade). 
Diversos foram os programas para erradicar o analfabetismo no decorrer dos anos, entretanto as desigualdades sociais impediram que muitos fossem assertivos ${ }^{6}$. Em um país que apresenta uma das piores concentrações de renda do mundo e a renda dos $20 \%$ mais ricos é 32 vezes maior que aquela dos $20 \%$ mais pobres, a distribuição da educação e do analfabetismo não poderia ser diferente. Assim, para o país como um todo, enquanto a taxa de analfabetismo nos domicílios cujo rendimento é superior a dez salários mínimos é de apenas 1,4\%, naqueles cujo rendimento é inferior a um salário mínimo é de quase $29 \%$. No Nordeste essa situação acentua-se: a taxa de analfabetismo das famílias mais pobres é vinte vezes maior que aquela das famílias mais ricas (INEP, Mapa do Analfabetismo, 2018). Importante dizer que os índices de evasão e reprovação ainda permanecem com maior ou menor incidência em grande parte dos estados brasileiros. Segundo dados do UNICEF (2018), 7,4 milhões de crianças têm dois ou mais anos de atraso escolar, a principal causa de abandono na escola.

Como apontado, dentre os obstáculos do ensino emergencial remoto também destacam-se as questões estruturais, ou seja, os problemas de acesso a computadores e de conexão com internet, a falta de espaço apropriado para o estudo a domicílio/em casa e a relação família-escola. Se na modalidade presencial já havia um hiato entre a escola e os núcleos familiares, no momento de singularidade - isolamento social - as distâncias aumentam e a dificuldade de professores entrarem em contato com os pais dos alunos torna-se maior. Outro fator a não se desconsiderar é o fato da baixa escolaridade dos familiares. Inúmeros são os relatos em que os responsáveis não conseguem acompanhar as demandas da escola.

Segundo a pesquisa TIC Domicílios, divulgada em 2019, apenas 44\% dos domicílios da zona rural brasileira têm acesso à internet. Na área urbana, o índice é maior: $70 \%$ dos lares estão conectados. Desse total a maior quantidade de casas conectadas encontra-se na Região Sudeste, entre 69,9 e 73,0\%, e a menor quantidade na Região Nordeste, entre 57,0 e 60,2\%. As diferenças ficam ainda mais evidentes ao se analisar cada classe social: entre os mais ricos (classes A e B), 96,5\% das casas têm sinal de internet; nos patamares mais baixos da pirâmide

\footnotetext{
${ }^{6}$ Dentre os Programas pode-se citar: Campanha de Educação de Adolescentes e Adultos (1947, Governo Eurico Gaspar Dutra); Campanha Nacional de Erradicação do Analfabetismo (1958, Governo Juscelino Kubitschek); Movimento de Educação de Base (1961, criado pela Conferência Nacional de Bispos do Brasil-CNBB); Programa Nacional de Alfabetização, valendo-se do método Paulo Freire (1964, Governo João Goulart); Movimento Brasileiro de Alfabetização (Mobral) (1968-1978, Governos da Ditadura Militar); Fundação Nacional de Educação de Jovens e Adultos-Educar (1985, Governo José Sarney); Programa Nacional de Alfabetização e Cidadania-Pnac (1990, Governo Fernando Collor de Mello); Declaração Mundial de Educação para Todos (assinada, em 1993, pelo Brasil, em Jomtien, Tailândia); Plano Decenal de Educação para Todos (1993, Governo Itamar Franco); e, finalmente, o Programa de Alfabetização Solidária (1997, Governo Fernando Henrique Cardoso). (INEP, Mapa do Analfabetismo, 2018).
} 
(classes D e E), 59\% não consegue navegar na rede. Já entre a população cuja renda familiar é inferior a 1 salário mínimo, $78 \%$ das pessoas com acesso à internet usam exclusivamente o celular.

No tocante ao acompanhamento familiar junto aos estudos, dados apresentados pelo Instituto Brasileiro de Geografia e Estatística (IBGE) em 2017 apresenta uma correlação entre o nível de escolaridade da família e a chance de o estudante concluir a universidade. Segundo o estudo, 69\% dos jovens cujos pais terminaram o Ensino Superior também concluíram a graduação. Por outro lado, a probabilidade de alguém que não frequentou a escola ter um filho com diploma universitário é de apenas 4,6\%.

Agrega-se também aos problemas sociais a fome e o não fornecimento de alimentos falta de merenda no período de pandemia. Sabe-se que em muitas situações essa porção alimentar é crucial para a sobrevivência de crianças e adolescentes no Brasil. De acordo com estatísticas do IBGE (2019), 9 milhões de brasileiros entre zero e 14 anos do Brasil vivem em situação de extrema pobreza. O Sistema de Vigilância Alimentar e Nutricional do Ministério da Saúde (SISVAM, 2019) identificou 207 mil crianças menores de cinco anos com desnutrição grave no Brasil.

Concomitante à fome, há outro óbice a ser enfrentado: desnutrição e obesidade infantil. As crianças brasileiras estão cada vez mais obesas, incluindo as de baixa renda. $\mathrm{O}$ excesso de peso não revela uma alimentação de qualidade. É, na verdade, sinal do contrário disso - há um aumento expressivo do consumo de alimentos baratos e ultraprocessados, ricos em calorias, mas pobres em nutrientes.

A impossibilidade de estar no ambiente escolar e a não frequência nas aulas também colabora com uma maior exposição à violência (sexual, física ou psicológica) dos estudantes. $\mathrm{O}$ isolamento social evidencia e aponta essa natureza de violência - dentro de casa e longe dos olhos externos - em razão da ausência do contato diário com a escola. Costumeiramente são os professores que apontam as centenas e milhares de atos de violências praticados contra adolescentes e crianças.

Entre 2014 e 2016, a Coordenação de Assuntos Internacionais e Proteção às crianças/UNICEF (2018) apresentou relatório que evidenciava o aumento grave de violência infradoméstica na epidemia do vírus ebola nos países contaminados. Com a pandemia da COVID-19, constata-se a necessidade de reforçar o sistema de garantia de seus direitos. Importante destacar que a violência sistemática contra crianças e adolescentes causa traumas e as consequências psicológicas serão vistas pós-pandemia. Visualizando esse contexto, o 
Brasil precisa melhorar as políticas públicas atuais e investir em novas políticas para realmente alcançar os excluídos e vulneráveis.

No quesito formação de professores para ministrar aulas online e as dificuldades em adaptar conteúdos programáticos, inúmeros são os problemas citados por parte dos educadores e gestores, já que a educação a distância pressupõe um tutor e o uso de diversos recursos midiático diluídos em tempos distintos, com atividade síncronas e assíncronas. $\mathrm{Na}$ educação remota que se desenvolve em diversos estados simplesmente o professor foi posto a transferir sua aula presencial para o digital.

Os próprios sistemas e redes de ensino apresentam dificuldades estruturais no tocante às tecnologias e, em se tratando de escola rural, a dificuldade é ainda maior. A falta de infraestrutura é um dos principais problemas apontados pelas escolas rurais do país para ter acesso à tecnologia. De acordo com a pesquisa TIC Educação 2018, realizada pelo Comitê Gestor da Internet no Brasil (CGI.br), 43\% dessas escolas não têm internet por falta de estrutura na região e $24 \%$ delas apontaram o alto custo da conexão.

Enquanto na zona urbana $98 \%$ das escolas têm ao menos um computador com acesso à internet, nas escolas rurais o índice cai para 34\%. E, mesmo que tenha computador conectado, nem sempre ele está disponível para os estudantes: $62 \%$ das escolas rurais não têm computador para uso dos alunos, aponta a pesquisa. (TIC EDUCAÇÃO, 2018)

Insta destacar também para o risco de crescimento do trabalho infantil, do abuso e da violência doméstica contra crianças e adolescentes e da gravidez precoce no período. Ademais, com a crise econômica que assola o Brasil, é necessário reforçar o ciclo intergeracional da pobreza, acentuado pela redução na renda das famílias, em razão da queda no investimento em educação ${ }^{7}$ (pelas famílias e pelo governo) e pela tendência de piora nas condições de saúde mental e de nutrição das crianças e jovens vulnerabilizados.

\section{Vozes de educadores em tempos de pandemia}

Dar vez e voz para um dos elos mais significativos da educação tem por finalidade reconhecer organicamente a função dos educadores. Dessa forma, o espaço de fala, ou melhor, o protagonismo de fala, torna-se necessário e significativo em face da possibilidade de dizer-se, narrar-se enquanto sujeito histórico e, posicionar-se como tal, ou seja, atentar para

7 A disponibilidade para custear a Educação Básica assenta-se no recolhimento de tributos na Federação brasileira. Com a queda súbita da atividade econômica em função da pandemia de covid-19, às redes de educação de todo o território nacional é provável a lógica da imposição de restrições fiscais, com menos recursos protegidos para a aplicação em despesas educacionais. 
quem atua diretamente com o processo de forma a reconhecer os indivíduos como responsáveis por suas ações.

Quanto à questão do protagonismo de fala é importante ressaltar que os professores(as) entrevistadas possuem mais de uma décadas de atuação nas escolas, ou seja, estão diretamente ligadas ao processo de ensino-aprendizagem. No período que antecederam ou logo após a entrevista, enfatizaram a importância de serem ouvidas, pois assim poderiam contar um pouco de suas experiências, e ter isso registrado, já que dificilmente teriam tal oportunidade.

Importante destacar que algumas categorias foram e permanecem silenciadas (crianças, indígenas, mulheres, negros e demais). Oportunizar espaços para que os educadores, e com destaque as mulheres-professoras tenham espaços para expor suas percepções, é uma forma de conferir legitimidade aos seus lugares de fala. Ao tratar da importância do lugar de fala, Ribeiro diz que: "não estamos falando de indivíduos necessariamente, mas das condições sociais que permitem ou não que esses grupos acessem lugares de cidadania" (RIBEIRO, 2017, p. 61). Djamila colabora,

[...] O falar não se restringe ao ato de emitir palavras, mas de poder existir. Pensamos lugar de fala como refutar a historiografia tradicional e a hierarquização de saberes consequente da hierarquia social. Quando falamos de direito à existência digna, à voz estamos falando de lócus social, de como esse lugar imposto dificulta a possibilidade de transcendência. Absolutamente não tem a ver com uma visão essencialista de que somente o negro pode falar sobre o racismo, por exemplo.

Pensar lugar de fala seria romper com o silêncio instituído para quem foi subalternizado, um movimento no sentido de romper com a hierarquia [...]

Há pessoas que dizem que o importante é a causa, ou uma possível "voz de ninguém", como se não fôssemos corporificados, marcados e deslegitimados pela norma colonizadora. Mas, comumente, só fala na voz de ninguém quem sempre teve voz e nunca precisou reivindicar sua humanidade (RIBEIRO, 2017, p. 64, 90).

Nesse sentido, diante do quadro de desvalorização e falta de reconhecimento social da educação como um todo e da profissão de professor, pode-se dizer que o lugar de fala do educador é diminuto, inferiorizado e subalternizado na maioria das vezes. No processo de construção das memórias coletivas, muitos são os silenciamentos, os esquecimentos e apagamentos, todos em consonância com as relações de poder dentro de uma determinada sociedade. Nesse interim, assentou-se a perspectiva metodológica de ouvir os protagonistas em tempos de pandemia.

No espaço onde se desenvolveu a pesquisa, Sul do Brasil, foram entrevistadas dez professores(as) atuantes na Escola de Educação Básica das redes privada (5 depoentes) e 
pública (cinco depoentes). Utilizou-se como mecanismo de contato a forma on-line (e-mail). A faixa etária dos depoentes indica entre 26 e 50 anos. Em relação à religião, o percentual de professoras que se dizem católicas é superior ao das demais religiões, 70\%. No quesito escolaridade, $90 \%$ das entrevistadas possuem curso de Licenciatura e Especialização em Educação. Das depoentes que atuam na rede pública, 100\% ocupa a condição de concursada.

A primeira questão, 'Conte-nos sobre sua trajetória de docência em tempos de pandemia', tenciona abrir possibilidades para os(as) entrevistados(as) narrarem-se, buscarem em suas memórias, experiências e vivências desse período. Neste ponto, as depoentes discorreram,

Bom, de um dia para outro nosso cotidiano foi alterado bruscamente. Levei algumas semanas para entender o que seria necessário realizar na e pela escola após o primeiro Decreto do Governador. A imprensa já alertava, mas enquanto não chega a nossa porta parece que não é bem assim [...] a primeira vez que participei de uma reunião pelo computador não falei nada. Apenas escutei. Acho que nem tinha o que falar. Alguns colegas falavam sem parar e, outros nada como eu. Comecei a pensar onde daria minhas aulas: na sala? Na cozinha? Depois veio a insegurança de falar e não ser compreendida e por fim saber acessar as Plataformas. Ah, um detalhe: meu computador não é tão moderno. Fui obrigada a comprar outro, mesmo sem ter programado e dinheiro naquele momento. (Depoente E 01. Educador de Escola Privada, 2020).

Já a segunda depoente E 02, destacou:

[...] às vezes estou preocupada com o conteúdo programático. Posteriormente ao trocar ideias com alguns colegas e acompanhar as lives, acho que, prioritariamente, esse é um momento de aprendermos juntos. De cuidar do outro, a olhar como a ferramenta tecnológica pode possibilitar o acesso à aprendizagem e ser um complemento ao encontro presencial que está tão sem significado, especialmente quando falamos para juventude. [...] temos que levar em conta também que os professores foram pegos de surpresa e alguns estão fatigados e adoecendo. Isso assusta e preocupa quem está nas escolas. (Educador de Escola Pública, 2020).

A segunda pergunta foi: Como vocês veem o ensino-aprendizagem da escola de atuação durante o período de distanciamento social? A depoente E 03 assim se manifesta:

Não posso avaliar agora se minhas aulas estão sendo com a qualidade esperada. Eu me esforço. Dedico muitas horas para preparar as aulas. Às vezes mais que em tempos de ensino presencial. Outras vezes acho que uso mais tempo para elaborar as aulas do que o periodo total de aulas que deveria ministrar. Estou insegura em muitos momentos, até porque não fui formada para dar aulas de forma virtual. Por outro lado, não temos assessoria da Secretaria para que a adaptação de alunos e professores aconteça de forma segura [...] o abandono que sofremos é antigo. Entra 
governo, sai governo e nós só fazemos parte nos discursos pré-eleições. (Educadora de Escola Pública, 2020)

A educadora E 04 também colabora:

Os dias não estão fáceis. Tenho medo do futuro. Tenho dúvidas que o que ensino seja o suficiente para que os alunos aprendam. $O$ apoio do Setor Pedagógico da Escola é eficiente. Nos auxiliam, marcam reuniões, podemos falar e solicitar ajuda, porém, o contato direto com os alunos é entre espaços que ficamos sozinhos [...] os alunos até participam. As tarefas são elaboradas pela maioria, mas tudo é muito incerto. (Educadora de Escola Privada, 2020).

Importante avaliar que ambas educadoras declaram não possuir segurança quanto à efetivação do processo de ensino-aprendizagem. A docente que atua no ensino privado declara-se assegurada enquanto acompanhamento pedagógico e enfatiza que há o acompanhamento da maioria dos alunos no tocante à realização das atividades. Insta assinalar que quando se fala em educação não se trata apenas de transmissão de conhecimento. Fala-se da cotidianidade, da vida, de oportunidades e da integração dos sujeitos ao meio em que vive.

A terceira e quarta pergunta centrava-se nas questões do uso do tempo na preparação de aulas e as tecnologias. As educadoras E 05 e E 06 assim se pronunciaram:

Não é comum eu ficar muito tempo em frente ao computador e muito menos na tela do celular. Agora fui empurrada para essa 'normalidade' imposta pela escola. Infelizmente não podemos opinar. De uma semana para outra fomos comunicados pela Direção e Coordenação que mudaríamos a forma de ensinar. Foi oferecido um curso de 30 horas. Muita informação e a promessa de termos assessoria [...] passou o tempo e, até tivemos assessoria, mas foi insuficiente. As dúvidas surgem quando estamos sozinhos. Bom, agora nunca estamos sozinhos. Temos os filhos, a casa e outros afazeres [...] mas, como vou chamar alguém da Coordenação se a dificuldade surge às 22:00? (Educadora E 05, Escola Privada, 2020).

São muitas as exigências e, quase nada de apoio e formação. Veja, eu realizei minha Graduação em tempos que poucos professores que ministravam aulas na Universidade tinham um computador. Imagina como era a realidade dos alunos (eu no caso!). Depois ao terminar a Graduação você centra em passar em um concurso, cumprir com responsabilidades as tarefas do ato de educar e assim o tempo passa e você não consegue acompanhar tudo. Outra questão é a remuneração do professor. Hoje tornase quase inviável investir em tecnologias quando nem sequer os salários são pagos em dia. E o pior é ver os gestores e até o governador apresentar em redes de comunicação as novas 'formas de ensinar' com o uso da tecnologia. Que tecnologia em um contexto que muitas crianças não têm nem o que comer? Outra dificuldade é a da percepção do indivíduo em relação à aprendizagem. Sabem que tem dificuldades e precisam do ensino, mas não priorizam estudar, simplesmente por viverem numa lógica de sobrevivência. Quando não se sabe o que se vai comer ou como se vai 
passar o dia o estudo fica em segundo plano. (Educadora E 06, Escola Privada, 2020).

Em ambas as falas das educadoras é possível constatar a falta de oportunidades na formação continuada para atuação com as tecnologias, bem como as dificuldades econômicas - baixos salários -, a fim de adquirir equipamentos para uso pessoal e de trabalho. Destaca-se também as desigualdades sociais observadas no contexto escolar brasileiro. As chances de um paciente preto ou pardo e analfabeto ${ }^{8}$ morrer em decorrência do novo coronavírus no Brasil são 3,8 vezes maiores do que de um paciente branco e com nível superior, apontou uma análise de quase 30 mil casos de internações pela Covid-19 feita pelo Núcleo de Operações e Inteligência em Saúde da PUC-Rio, destacando o impacto das desigualdades sociais na letalidade da doença no país.

O estudo aponta que quanto maior o nível de escolaridade, menor a letalidade, e este efeito interliga-se às desigualdades sociais-raciais, às diferenças de renda, que geram disparidades no acesso aos serviços básicos sanitários e de saúde. De acordo com dados do Ministério da Saúde (maio de 2020), brancos representavam 51,4\% do total de internados por Covid-19 no país até 18 de maio, enquanto pretos e pardos eram 46,7\%. Em termos de óbitos, pretos e pardos representavam $54,8 \%$ e brancos $43,1 \%$.

A quinta pergunta relacionava-se à garantia do direito à educação. As educadoras $\mathrm{E} 07$ e E 08 enunciam:

Grande parte da população brasileira tem conhecimento que a educação é um direito. Um Direito Humano. Está na Constituição, entretanto em muitas vezes esse direito é negado ou negligenciado. Eu sou professora há mais de uma década e vivenciei momentos de chamar os alunos para escola porque tinham que trabalhar. Outros porque a própria escola os excluía. Se for uma criança indígena ou negra os problemas aumentam [...] parte da sociedade colabora com esse processo de expulsão dessas crianças da escola quando afirmam que lugar de pobre é trabalhar e não estudar. É muito desanimador ouvir isso até hoje. As vezes acho que as pessoas não conseguem se ver como portadoras de direitos. Quando eu digo portadora é todos, não somente algumas classes. Outra questão me preocupa é o pós-pandemia. Se antes do isolamento já sofríamos os mais diversos cortes no orçamento, imagina agora. (Educadora E 07, Escola Pública, 2020).

Estar numa escola é um direito de todas as crianças. Esse já é um pensamento consolidado, mas há muitas negações impostas sobre a educação brasileira que às vezes nos perguntamos até que ponto o Direito à educação é para todos. É importante estar descrito na Constituição Federal e nas Convenções Internacionais: educação é um Direito Humano, mas até

${ }^{8} \mathrm{O}$ estudo também indica que entre os pacientes internados, quando a análise é feita pela escolaridade, pessoas com nível superior representavam $22 \%$ das mortes analisadas, enquanto os sem escolaridade chegavam a $71,31 \%$ (PUCRJ, 2020). 
que ponto isso se cumpre? Agora mesmo vivemos amedrontados com a possibilidade do fim do Fundeb [...] (Educadora E 08, Escola Pública, 2020).

Das dez depoentes entrevistadas, todas afirmaram ter ciência de que a educação é um Direito Humano. Porém, destacam as inúmeras variáveis que inibem o desenvolvimento pleno desse direito em grande parte das escolas. A preocupação com os cortes e contingenciamentos também estão entre as preocupações cotidianas. O provável e potencial impacto financeiro e fiscal da pandemia de Covid-19 na educação é relatado como entendimento de que o financiamento educacional no Brasil é fundamentalmente caracterizado por ter como fonte principal um conjunto de tributos com vinculação constitucional.

De acordo com a Constituição Federal, em seu art. 212, os Estados, o Distrito Federal e os municípios precisam aplicar em manutenção e desenvolvimento do ensino (MDE) pelo menos $25 \%$ das suas receitas resultantes de impostos e transferências. A União, por sua vez, deve aplicar pelo menos $18 \%$ da sua receita de impostos - regra temporariamente modificada pela Emenda Constitucional (EC) $n^{\circ}$ 95/2016. Os recursos vinculados financiam despesas tanto na Educação Básica quanto no Ensino Superior e representam $72 \%$ do total de investimento público em educação (HOOGERBRUGGE, 2020, p. 9).

Os principais impostos e transferências vinculados à educação são o Imposto sobre Circulação de Mercadorias e Serviços (ICMS), de competência estadual, com fração de um quarto da arrecadação distribuída aos municípios, o Fundo de Participação dos Municípios (FPM), o Fundo de Participação dos Estados (FPE), o Imposto sobre Serviços (ISS) - de competência municipal - e o já mencionado Salário-Educação. Juntas, suas vinculações para a educação somaram R\$ 196 bilhões em 2018 (SECRETARIA DO TESOURO NACIONAL, 2019).

Quanto ao possível risco adicional de impacto fiscal com eventual fim do Fundeb, acentua-se que essa política tem vigência constitucional até 31 de dezembro de 2020 , e caso não tenha renovação votada pelo Congresso Nacional nesse ano, o Fundeb expirará. Nesse cenário, o investimento por aluno cairia mais da metade em 1.220 municípios (cujas redes de educação somam 7,5 milhões de alunos[as]).

Nesses municípios, o pagamento dos(as) profissionais da educação ficaria inviável, bem como boa parte dos gastos de manutenção que permitem que as escolas fiquem abertas. O fim do Fundeb também afetaria as redes estaduais de educação de duas formas: costumeiramente, nove redes estaduais recebem recursos federais da chamada “complementação da União" ao Fundeb, e seu fim encerraria também tal transferência; além disso, a desorganização das redes municipais levaria a um aumento bastante significativo da 
demanda por vagas nas redes estaduais, sobrecarregando esses sistemas educacionais (HOOGERBRUGGE, 2020, p. 10).

Outro elemento perguntado nas entrevistas foram as perspectivas de retorno às aulas após o período de isolamento social. As educadoras E 09 e E 10 discorreram:

\begin{abstract}
[...] estamos ansiosos e ao mesmo tempo esperançosos. Ansiosos para retomar as aulas presenciais e não ter condições mínimas de cuidados (álcool gel, máscaras e outros). Esperançosos pelo fato de rever os alunos e colaborar com o processo de ensino de forma mais próxima. Surgem muitas perguntas: como iremos ensinar? O que iremos ensinar se o entrono das crianças e o mundo mudou? (Educadora E 09, Escola Privada, 2020).
\end{abstract}

São muitas as dúvidas. Teremos materiais para desenvolver as aulas por ensino remoto e presencial? Haverá formação aos professores da rede estadual e municipal e apoio dos gestores para enfrentar o novo mundo que se apresentou após o primeiro dia de isolamento? Como os alunos irão se comportar frente as normas de controle e cuidado (isolamento)? Todos os alunos irão voltar? E as crianças pobres que não conseguiram acompanhar as atividades por falta de condições como a fome ou falta de computador e internet? (Educadora E 10, Escola Pública, 2020).

Em síntese, na totalidade as depoentes educadoras afirmaram que possuem mais ansiedades e preocupações do que certezas. No quesito estrutura escolar pós-pandemia é importante assinalar que as redes contam com orçamentos contingenciados ou reduzidos em relação à dotação inicial, embora mais investimentos sejam necessários para lidar com a crise da pandemia. Porém, em breve, as redes deverão planejar e executar a reabertura das escolas e a retomada do ensino presencial, no momento em que os órgãos de saúde e os governos estaduais sinalizarem a viabilidade e a segurança do fim do isolamento.

\title{
Considerações finais
}

Em menos de duas semanas professores e alunos de instituições educacionais públicas e privadas transferiram suas salas de aula para o ciberespaço. Iniciou-se uma corrida para dar conta do conteúdo que precisa ser trabalhado no ano letivo e, para isso, professores e alunos começaram a utilizar para sua comunicação e-mail, Facebook, Whatsapp, e também plataformas on line para maior interação remota. Estão sendo gravadas vídeo aulas para serem disponibilizadas aos estudantes. Sabe-se da profunda desigualdade presente na educação brasileira: quanto mais recursos as redes de ensino possuem, maior a possibilidade de comunicação com seus alunos.

RIAEE - Revista Ibero-Americana de Estudos em Educação, Araraquara, v. 15, n. 4, p. 1750-1768, out./dez. 2020. e-ISSN: $1982-5587$. 
A tríade utilizada como campo de reflexão nesse estudo, 'Direitos Humanos, Educação e Pandemia', justifica-se pelo universo de perguntas que os mais diversos segmentos científicos têm sido postos a responder após a suspensão das atividades de ensino em todo Brasil. Nessa seara, a escolha por esse ator dentro do sistema escolar deve-se à crença do efeito multiplicador que os docentes têm na efetivação dos Direitos Humanos, e assim assinala-se a importância de ouvi-los. Ou seja, da mesma forma que no cotidiano escolar é o professor quem tem contato mais próximo com os alunos, agora será oficialmente a ponte entre todo o sistema de educação e os estudantes.

A suspensão das aulas é uma medida comum às duas redes presentes no estudo (privada e estadual), e num primeiro momento pode-se dizer que a rede particular mostra estar mais preparada para o momento, uma vez que $75 \%$ dos depoentes que atuam em escolas privadas afirmaram possuir suporte por parte das Direções e Coordenações para desenvolver ensino emergencial remoto ou educação a distância para os alunos.

No outro lado, os educadores da rede pública estadual, apenas 30\% afirmou estar seguro com as novas práticas. Muitos denunciam que estão sendo obrigados para o exercício das novas atribuições e funções. A diferença pode ser explicada especificamente em razão de desigualdade de condições de infraestrutura e formação de professores para o uso pedagógico de tecnologia.

Essas experiências relatadas pelos educadores indicam que o processo de ensinoaprendizagem em tempos de pandemia é mais de incertezas que de certezas, e que grande parte não possui condições de avaliar sua atuação no processo de ensino. Que a atuação virtual é uma possibilidade de manter o contato com os alunos, mas que exige um grande esforço emocional e estrutural que pode comprometer o processo de ensino, bem como a saúde dos professores. Todos, ou seja, 100\% dos depoentes dessa amostragem afirmaram que se sentem inseguros e pressionados nas ações pedagógicas quando se faz uso das tecnologias. Por outro lado, a maioria absoluta afirma que possui certeza que a educação é um Direito Humanos que precisa ser reiterado em tempos de flexibilização de direitos, mesmo em se tratando de Direitos Fundamentais.

Importante também destacar o abandono referenciado pelos educadores que atuam na rede pública, bem como o uso do direito à educação nos espaços políticos. Parte dos eleitos faz uso de discursos propositivos durante as campanhas eleitorais e descumpre seus projetos e planos de governo ao assumir o poder. Também merece destaque o fato de que, apesar de $70 \%$ dos respondentes afirmarem usar o momento para organizar a vida pessoal e familiar, $50 \%$ também pontuaram que estão estudando, seja preparando aulas, fazendo cursos online e 
construindo ou organizando materiais de ensino. Entre as principais fontes de informação utilizadas estão a internet (70\%) e a televisão (50\%).

\section{REFERÊNCIAS}

ALMEIDA, J. R. P. de. História da instrução pública no Brasil, 1500-1889. São Paulo: Ed. da PUC; Brasília: MEC-Inep 2000. Edição original em francês de 1889.

ALMEIDA, S. Pode o subalterno falar? Belo Horizonte: Editora da UFMG, 2012.

BRASIL. Ministério Nacional de Economia. Secretaria do Tesouro Nacional. Receitas das unidades federativas e cálculo de manutenção e desenvolvimento do ensino (MDE).

Brasília, 2018. Disponível em: http://www.tesouro.fazenda.gov.br/. Acesso em: 06 jun. 2020.

BRASIL. Constituição Federal 1988. Disponível em:

https://www2.senado.leg.br/bdsf/bitstream/handle/id/518231/CF88_Livro_EC91_2016.pdf. Acesso em: 06 jun. 2020.

BRASIL. INEP. Instituto Nacional de Estudos e Pesquisas Educacionais Anísio Teixeira. Mapa do Analfabetismo no Brasil. Disponível em:

http://portal.inep.gov.br/documents/186968/485745/Mapa+do+analfabetismo+no+Brasil/a53a c9ee-c0c0-4727-b216-035c65c45e1b?version=1.3. Acesso em: 24 maio 2020.

BALLESTRIN, L. América Latina e o giro decolonial. Revista Brasileira de Ciência Política, n. 11, p. 89-117, 2013.

BRAGATO, F. F. Para além do discurso eurocêntrico dos direitos humanos: contribuições da descolonialidade. Novos Estudos Jurídicos, [S.1.], v. 19, n. 1, p. 201-230, abr. 2014. Disponível em: https://siaiap32.univali.br/seer/index.php/nej/article/view/5548. Acesso em: 14 maio 2020.

CASTRO-GÓMEZ, S. Ciências sociais, violência epistêmica e o problema da "invenção do outro". In: LANDER, E. (Org.). A colonialidade do saber: eurocentrismo e ciências sociais. Perspectivas latino-americanas. Buenos Aires: Clacso, 2005.

CGI. Comitê Gestor da Internet no Brasil. Relatórios. Disponível em: https://www.cgi.br/. Acesso em: 30 maio 2020.

DUSSEL, Enrique. Europa, modernidade e eurocentrismo. In: LANDER, Edgardo (Org.) A colonialidade do saber: eurocentrismo e ciências sociais. Perspectivas latino-americanas. Buenos Aires: Clacso, 2005.

FIGUEIREDO, C. V. da S. Estudos Subalternos: uma introdução. Raído, Dourados, MS, v. 4, n. 7, p. 83-92, jan./jun. 2010. Disponível em:

http://ojs.ufgd.edu.br/index.php/Raido/article/viewFile/619/522. Acesso em: 01 jun. 2020.

RIAEE - Revista Ibero-Americana de Estudos em Educação, Araraquara, v. 15, n. 4, p. 1750-1768, out./dez. 2020. e-ISSN: $1982-5587$. 
HOOGERBRUGGE, L. F. Todos pela Educação. COVID-19 Impacto Fiscal na Educação Básica. O cenário de receitas e despesas nas redes de educação em 2020, 2020. Disponível em: http://www.i-mpr.com/s/0603/12.pdf. Acesso em: 06 jun. 2020.

LUGONES, M. Rumo a um feminismo descolonial. Estudos feministas, Florianópolis, v. 22, n. 3, p. 935-952, 2014.

NERI, M. C. A escalada da desigualdade. Qual foi o Impacto da Crise sobre a Distribuição de Renda e a Pobreza? Rio de Janeiro, 2019. Disponível em: https://cps.fgv.br/desigualdade. Acesso em: 18 maio 2020 .

QUIJANO, A. Colonialidade do poder, Eurocentrismo e América Latina. Buenos Aires: CLACSO, 2005. p. 117-142. Disponível em: http://biblioteca.clacso.edu.ar/clacso/sursur/20100624103322/12_Quijano.pdf. Acesso em: 18 maio 2020.

RIBEIRO, D. O que é lugar de fala? Coleção Feminismos Plurais. Belo Horizonte: Editora Letramento, 2017.

SANTOS, B. de S. Para além do pensamento abissal: das linhas globais a uma ecologia de saberes. Novos estudos - CEBRAP, São Paulo, n. 79, p. 71-94, nov. 2007. Disponível em: http://www.scielo.br/scielo.php?script=sci_arttext\&pid=S010133002007000300004\&lng=en\&nrm=iso. Acesso em: 10 maio 2020.

SISVAM. Sistema de Vigilância Alimentar e Nutricional do Ministério da Saúde. Relatórios. Brasília, 2019. Disponível em: http://sisaps.saude.gov.br/sisvan/relatoriopublico/index. Acesso em: 31 maio 2020.

UNI. Relatório Anual do UNICEF Brasil. A infância e você. Brasília, Ano 14, n. 39, 2018. Disponível em: https://www.unicef.org/brazil/sites/unicef.org.brazil/files/201903/UNI39_RA2017.pdf. Acesso em: 31 maio 2020.

\section{Como referenciar este artigo}

WENCZENOVICZ, T. J. Ensino a distância, dificuldades presenciais: perspectivas em tempos de COVID-19. Revista Ibero-Americana de Estudos em Educação, Araraquara, v. 15 , n. 4, p. 1750-1768, out./dez. 2020. e-ISSN: 1982-5587. DOI: https://doi.org/10.21723/riaee.v15i4.13761

Submetido em: 20/04/2020

Revisões requeridas em: 10/06/2020

Aprovado em: 25/07/2020

Publicado em: 30/08/2020 
RIAEE - Revista Ibero-Americana de Estudos em Educação, Araraquara, v. 15, n. 4, p. 1750-1768, out./dez. 2020. e-ISSN: $1982-5587$. DOI: https://doi.org/10.21723/riaee.v15i4.13761 